FEDERAL RESERVE BANK OF SAN FRANCISCO

WORKING PAPER SERIES

\title{
The Impact of COVID on Potential Output
}

\author{
John Fernald \\ Federal Reserve Bank of San Francisco \\ Huiyu Li \\ Federal Reserve Bank of San Francisco \\ March 2021 \\ Working Paper 2021-09 \\ https://www.frbsf.org/economic-research/publications/working-papers/2021/09/
}

\section{Suggested citation:}

Fernald, John, Huiyu Li. 2021 "The Impact of COVID on Potential Output," Federal Reserve Bank of San Francisco Working Paper 2021-09.

https://doi.org/10.24148/wp2021-09

The views in this paper are solely the responsibility of the authors and should not be interpreted as reflecting the views of the Federal Reserve Bank of San Francisco or the Board of Governors of the Federal Reserve System. 


\title{
The Impact of COVID on Potential Output
}

\author{
John Fernald Huiyu Li*
}

Draft: March 22, 2021

\begin{abstract}
The level of potential output is likely to be subdued post-COVID relative to its pre-pandemic estimates. Most clearly, capital input and full-employment labor will both be lower than they previously were. Quantitatively, however, these effects appear relatively modest. In the long run, labor scarring could lead to lower levels of employment, but the slow pre-recession pace of GDP growth is unlikely to be substantially affected.
\end{abstract}

Keywords: Growth accounting, productivity, potential output.

JEL codes: E01, E23, E24, O47

${ }^{*}$ Fernald: Federal Reserve Bank of San Francisco and INSEAD; Li: Federal Reserve Bank of San Francisco. We thank Mitchell Ochse for excellent research support. Any opinions and conclusions expressed herein are those of the authors and do not necessarily represent the views of the Federal Reserve System. 


\section{Introduction}

How will COVID-19 affect the level and growth rate of U.S. GDP going forward? The answer to this question matters directly for well-being. But it also matters for policy makers. For example, the level and growth of potential output has important implications for monetary policymakers assessing the degree of slack and inflationary pressures.

This paper provides a simple growth-accounting framework to think through the short-, medium-, and longer-run channels through which COVID-19 might affect potential output. We can quantify some of the channels. These "known knowns" suggest a relatively modest impact so far. We discuss a range of other channels that are "known unknowns": The importance-and, in some cases, even the sign-of these channels is necessarily speculative. ${ }^{1}$

Even before the coronavirus wreaked its havoc, the normal pace of growth appeared subdued relative to history (See, for example, (Fernald and Li, 2019)). We argue that COVID-19 has not yet caused changes that push this sluggish "longer-run" growth-rate prediction substantially off course. Labor-supply growth will remain low and COVID does not, on its own, seem likely to lead to sharp changes in research effort or in the idea production function that would push us away from the slow-productivity-growth trajectory. Our point forecast is that longer-run (say, 5 to 10 years out) GDP growth is likely to be a little above $1 \frac{1}{2}$ percent.

Of course, even if the growth rate isn't much affected, there can be important changes in the level of potential. After the Great Recession, for example, potential output appeared to be harmed for a time by the substantial reduction in capital accumulation and, potentially, by disruptions to labor markets. In the near term, our best guess is that COVID-19 will modestly reduce the level of potential output through headwinds to labor, capital, and

\footnotetext{
${ }^{1}$ By definition, we do not discuss unknown unknowns. Historically, unanticipated factors have probably been the most important determinants of changes in potential output.
} 
total factor productivity (TFP). Labor supply is held back by child care demands and other sources. Investment has fallen, which hits the economy's productive capacity; and much of the apparent strength in investment in information technology equipment reflects the need to duplicate idle office capital to allow workers to work from home. The level of TFP is likely to be held down by adjustment costs associated with the transition to work-for-home, as well as from the need to adjust supply chains. ${ }^{2}$

Depending in part on how long the downturn continues, there is the risk of hysteresis. It follows that the ultimate effect on the level of potential output may depend on the countercyclical effects of monetary and fiscal policy that seek to limit the depth of the pandemic-induced downturn. ${ }^{3}$

Throughout this paper, we focus on a production-function definition of potential output: the level of output given actual capital and technology, if capital and labor input (both hours and labor quality) were utilized at "normal" levels. This is the definition used by the Congressional Budget Office (CBO) and many policy organizations. It is related to, but conceptually a little different than, the flexible-price equilibrium level, because labor supply or factor utilization might optimally vary in response to some shocks in a way not allowed for with the production-function approach. Nevertheless, Kiley (2013) argues that the output gap in a carefully specified dynamic stochastic general equilibrium model, the natural-rate measure of the output gap comoves reasonably closely with a production-function based measure. (See Fernald (2015) for further discussion.) In any case, in the long run, the two approaches are equivalent.

\footnotetext{
${ }^{2}$ Bloom et al. (2020b) suggest that the level of U.K. TFP might persistently be reduced, based on a large survey of firms.

${ }^{3}$ After the Great Recession, the persistence of the adverse effects on the level of potential output are controversial. Fernald et al. (2017) argue that temporary effects through capital accumulation and labor-market disruptions were not persistent. They find that, by 2016, most of the disappointing U.S. output performance relative to pre-Great-Recession trends reflected non-recession factors. Cerra et al. (2020) and others, in contrast, interpret the evidence as favoring hysteresis. Jordá et al. (2020b) discuss additional references on the persistent effects of demand shocks on potential output.
} 
Figure 1: Level and growth rate effects on potential output

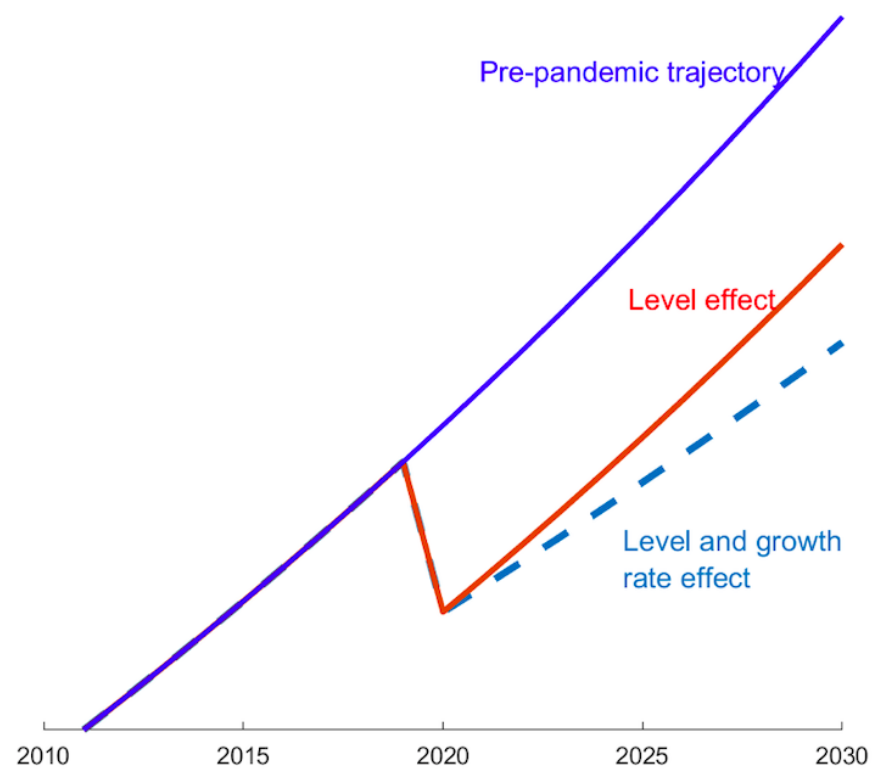

Notes: Figure shows a stylized representation of possible potential output paths following COVID-19.

Figure 1 motivates the organization of the paper. Section 2 discusses the growth-accounting framework we use to understand potential output at a point in time, as well as over time. The framework thus describes the position and slope of the lines in the figure. Section 3 provides background facts on the pre-pandemic trajectory of the economy-the blue line in the figure. We then discuss possible effects on the level of potential in Section 4-the red line in the figure. These level effects may come through capital, labor, or TFP. For a number of the channels we can quantify the likely effects, which are most likely modestly negative. As shown, the level effects are permanent, though many of them are likely to be temporary. In the red line, the longer-run growth rate is unchanged from its pre-pandemic trajectory. But the pandemic might also affect the growth rate. So, in Section 5, we then discuss potential reasons why the longer-run growth rate of the economy might change. The dashed line shows a post-COVID change in the growth rate. In the figure, the growth-rate change is also associated with a level effect on the "jumping off point" for the 
change in growth. Such a level effect might or might not occur in practice.

\section{Potential output accounting framework}

A standard way to think about potential output growth is in terms of growth in inputs as well as in the efficiency with which those inputs are used. The following constant-returns aggregate production function, in growth-rate terms, provides the organizing framework for the rest of the paper:

$$
d y=\alpha d k+(1-\alpha)(d h+d l q)+d t f p
$$

All variables, including factor shares, have time subscripts that we omit for simplicity. $d y$ is output growth, $\alpha$ is capital's output elasticity (and, under standard conditions, its factor share), and $d k$ is capital-input growth, "Effective" labor growth is the sum of hours growth, $d h$, and labor-quality growth, $d l q$. In the growth-accounting literature, labor quality captures the effect of education and experience on the labor force (Jorgenson et al., 1987; Bosler et al., 2017). ${ }^{4} d t f p$ is total-factor-productivity growth, which is defined implicitly by this equation as output growth not explained by share-weighted input growth. In that sense, it is a broad measure of technology or efficiency. This measure of technology reflects any changes in factor misallocation as well as any mismeasurement of factor shares or factor inputs.

By estimating or projecting the variables on the right-hand side of (1), we can estimate potential growth. In particular, we can estimate what labor and TFP growth would be if the economy were at "full employment," and we can estimate what actual capital input is based on investment flows (and project it using estimates of future investment). For this reason, (1) provides a useful

\footnotetext{
${ }^{4}$ More formally, suppose the production function has $N$ types of labor, so that $Y=$ $F\left(K, H_{1}, H_{2}, \ldots H_{N}\right)$. Then the standard Solow accounting that leads to equation (1) would imply $d y=\alpha d k+(1-\alpha) \sum_{i} s_{L i} d h_{i} /(1-\alpha)+d t f p$, where $s_{L i}$ is the revenue share of labor input $i$. If $H=\sum_{i} H_{i}$ is total hours worked, then $d l q \equiv \sum_{i} s_{L i} d h_{i} /(1-\alpha)-d h$.
} 
organizing framework for thinking about how COVID might affect potential over the next few years.

It will be useful in the long run to write growth in output identically as the sum of growth in labor productivity and hours:

$$
d y=(d y-d h)+d h .
$$

In standard growth models, steady-state labor-productivity growth, $d y-d h$, depends solely on TFP growth. The reason is that capital growth from equation (1) is endogenous and depends on growth in technology and in labor input. Specifically, rearranging the production function (1), labor productivity is:

$$
d y-d h=\alpha(d k-d h-d l q)+d l q+d t f p .
$$

In the standard one-sector model, steady-state capital per quality-adjusted hour grows at the rate of labor-augmenting technical progress: $d k-d h-d l q=$ $d t f p /(1-\alpha)$. It then follows from equation (3) that

$$
d y-d h=\frac{d t f p}{1-\alpha}+d l q .
$$

Thus, in the long run, labor productivity depends primarily on technology, whereas hours growth $d h$ depends primarily on demographics. Of course, there are models where TFP growth itself depends on demographics. Perhaps most obviously, in semi-endogenous growth models such as Jones (2002), steady-state TFP growth depends completely on demographics: TFP comes from ideas, and ideas come from people. However, even in that model, other factors-most importantly, rising research effort, though also changes in the idea production function-can matter for very long periods: according to that model, the economy has been growing faster than steady-state for at least a century and a half (Fernald and Jones, 2014). In any case, although we assume in what follows that TFP growth is largely independent of demographics over 
the next decade or two, allowing for demographics to affect TFP growth would reinforce the slow-growth message of our paper. That is, U.S. and advanced economy growth in the working age population is expected to be slow (or even negative) in coming decades which, through reduced idea-creation, lower firm-dynamism, or other channels, could put downward pressure on TFP growth $^{5}$

However, in the quarters or even years immediately following the COVID recession (or other downturns), equation (2) is less useful as a guide to near-term potential output. The reason is that observed labor productivity growth is substantially affected by the business cycle. Because the forces do not all act in the same direction, it can be more challenging to easily assess the full-employment level and growth rate of labor productivity. (see, e.g., Fernald and Wang 2016). ${ }^{6}$ Of course, one can calculate the implied potential (or structural) growth in labor productivity. But one needs to use (1) to estimate potential output growth first.

Thus, in thinking about potential output in the near term, we continue to focus on equation (1). For the longer-term, however, where capital is endogenous to other supply-side impulses, we think about equation (4).

\footnotetext{
${ }^{5}$ In addition to Jones (2002) and Fernald and Jones (2014), Peters and Walsh (2019)) is another recent example, with references. Those authors write down a model of firm dynamics, in which lower population growth leads to reduced creative destruction and productivity growth.

${ }^{6}$ On one hand, measured TFP tends to be procyclical because of fluctuations in factor utilization: Variations in capital's workweek and labor effort. On the other hand, capital deepening rises sharply (countercyclically), because labor falls. Ceteris paribus, the capitaldeepening effect raises labor productivity. (Note that this is the effect of diminishing marginal product of labor; it's why we typically draw labor demand curves as downward sloping). In addition, another countercyclical force is that, in downturns, including during COVID, workers with less education and experience disproportionately lose jobs. That, in turn, provides a countercyclical boost to the level of skills-the "quality" —of the people who keep their jobs. Higher workforce skills again works to raise the level of labor productivity.
} 


\section{Longer-run growth before COVID}

We start with some background on longer-run growth in the U.S. before the pandemic. So, in this section, we use the decomposition in equation (2) that focuses on labor productivity and hours. The section establishes some "facts" about pre-pandemic growth in productivity, hours, and GDP. These include discussing why, prior to the pandemic, the outlook for longer-run U.S. growth appeared likely to be slow.

Table 1 shows total-economy output, hours worked, and output per hour for selected periods since World War II. The periods highlight notable variations in productivity growth. ${ }^{7}$ Column (3) highlights how productivity growth has shifted between normal and exceptional periods (Fernald, 2016). Productivity growth was fast from 1948 to 1973, with GDP per hour growth of about $2 \frac{3}{4}$ percent. Productivity growth then slowed abruptly to only about $1 / 1{ }_{4}$ percent from 1973 to 1995. The Internet and other innovations related to information technology then boosted productivity to about $2 \frac{1}{2}$ percent for about a decade.

Since 2004, productivity growth has been slow once again, on the order of $1 \frac{1}{4}$ percent. Thus, prior the pandemic, the U.S. economy was in a slow-growth regime. Regimes generally appear persistent-lasting a decade or longer. If the regime switches follow a Markov process, then the likelihood of a regime switch does not depend on how long we have been in the current regime. Foerster and Matthes (2020) estimate, from TFP data, that both high and low TFP-growth regimes are expected to last about 15 years.

The regimes view is consistent with the view that unusually influential innovations-such as the electric dynamo, internal combustion engine, and the Internet-may lead to a host of complementary innovations that boost productivity growth broadly for a time. But the exceptional gains eventually

\footnotetext{
${ }^{7}$ Fernald (2015) discusses break tests on productivity that roughly correspond to the periods shown. Kahn and Rich (2007) use a multivariate regime-switching model-with labor productivity, real wages, consumption per hour, and (detrended) hours. Their updated estimates, available on Kahn's web page, find that the mid-2000s productivity slowdown occurred at the end of 2004.
} 
Table 1: Real GDP, hours, and productivity

\begin{tabular}{|c|c|c|c|}
\hline & $\begin{array}{c}\text { GDP } \\
(1)\end{array}$ & $\begin{array}{c}\text { hours } \\
\text { (2) }\end{array}$ & $\begin{array}{c}\text { GDP per } \\
\text { hour } \\
(3)\end{array}$ \\
\hline 1. $1948-1973$ & 3.95 & 1.19 & 2.76 \\
\hline 2. $1973-1995$ & 2.84 & 1.56 & 1.29 \\
\hline 3. $1995-2004$ & 3.38 & 0.86 & 2.52 \\
\hline 4. $2004-2019$ & 1.54 & 0.31 & 1.23 \\
\hline 5. Slow prod. regime $(1973-95,2004-19)$ & 2.34 & 1.07 & 1.27 \\
\hline 6. Fast prod. regime $(1948-73,1995-04)$ & 3.80 & 1.10 & 2.70 \\
\hline 7. Benchmark $g^{\star}$ projection (2004-18) & 1.55 & 0.32 & 1.23 \\
\hline
\end{tabular}

Notes: Entries are average percent change (100 x log change) per year over period shown. "GDP" in column (1) is the average of growth in gross domestic product and gross domestic income (GDI) from the BEA. Total economy hours in column (2) are from the BLS. The benchmark $g^{\star}$ projection in row (7) assumes total-economy hours grow at the CBO's estimated 2027-31 labor-force growth rate, while real GDP per hour grows at its average 2004-19 pace from row (4). Each subperiod is named by the first and last years of data used.

run out and the fast-growth regime ends.

Of course, productivity is highly uncertain in both a statistical and an economic sense. Under the regimes view of productivity growth, much of the statistical uncertainty is about which regime we will be in. Neither economists nor statisticians have a good track record of forecasting changes in trend productivity growth, which is why a Markov structure for the transition matrix is a reasonable modeling choice. For example, perhaps artificial intelligence and robots will eventually bring a massive productivity payoff-but we do not know when it will happen. ${ }^{8}$ In addition, even within a regime, productivity is

\footnotetext{
${ }^{8}$ The speed of adoption and diffusion is key. For example, in the 1990s, there was the popular saying, "The Internet changes everything." More than two decades on, it is true that the Internet has transformed much of human life, to the point where it is hard to imagine life without the Internet. And yet, the pace of transformation was much slower than the Internet evangelists at the time expected, and productivity growth has been only modest since 2004, even as the transformation continued.
} 
inherently volatile from year to year.

The final row of the table shows a fairly straightforward, if pessimistic, benchmark projection for potential, or longer-run, GDP growth, $g^{*}$. We think of the longer run as the period over which a steady-state projection for labor productivity (in equations (2) and (3)) is a good approximation. For the sake of concreteness, we think of the "longer run" as at least five or six years, in order to be consistent with the Federal Open Market Committee's Summary of Economic Projections. ${ }^{9}$ The projection in the first column is that GDP will grow slightly above $1 \frac{1}{2}$ percent per year-very close to the actual average growth rate of only 1.54 percent per year from 2004 to 2019.

That first column is the sum of the second and third columns. As the second column shows, demographics are the key reason to expect future trend growth to be slow. The number shown, 0.32 percent per year growth in hours, is the Congressional Budget Office's (CBO) forecast for labor-force growth six to ten years out (CBO, 2021). This forecast accounts for population aging, participation decisions of different groups, and immigration.

Projections for productivity in the final row of column (3) are arguably more contentious. But as noted above, the productivity-regimes point of view suggests that a reasonable modal guess is that productivity growth continues at its current slow pace for the next decade or longer. During previous slow growth regimes, including during the 2004-2019 period, GDP per hour rose around $1 \frac{1}{4}$ percent per year. (Of course, even if the modal expectation is that we will stay in this regime for the next 15 years, the mean expectation of growth over this period will incorporate the probability of a regime switch.)

Thus, the benchmark in the table is that GDP per hour continues to grow at

\footnotetext{
${ }^{9}$ How long is "longer run" depends on capital adjustment costs that might slow the response of capital growth to the state of the economy. In CBO projections from February 1, 2021, potential labor productivity is relatively constant after five years.
} 
the 1.23 percent pace that it grew from 2004 to $2019 .{ }^{10}$ The resulting benchmark point estimate that future growth of GDP will be 1.55 percent corresponds to the slope of the blue "pre-pandemic trajectory" line in Figure 1. We discuss in Section 5 whether COVID is likely to push that pace off course.

\section{Level effects from COVID}

In this section, we discuss quantitative and qualitative effects from COVID on the level of potential output. Conceptually, this corresponds to the red "level effects" line in Figure 1. Following equation (1), we organize the discussion on capital, labor, and TFP.

Under each of these factors, there are multiple potential channels. Before diving into the details, we preview the results in Table 2. Panel A shows channels for which we can gauge plausible magnitudes. The time horizons vary from the near term (which we think of as being 2021) to the very long run (which, in the case of school closures that reduce future human capital, correspond to the year 2045). But in the near term, potential output is plausibly reduced by about a percentage point. Some if not all of these effects are likely to diminish over time as the economy returns to a post-pandemic normal. ${ }^{11}$

Such effects appear modest relative to the aftermath of the Great Recession. For example, Fernald (2015) estimates that shortfalls in capital accumulation alone reduced potential output by several percent during and right after the

\footnotetext{
${ }^{10}$ Fernald (2016) provides a more formal analysis of growth fundamentals and argues that two economic factors not separately analyzed here largely offset each other. On the one hand, that detailed growth model suggests that physical and intangible capital deepening should provide a larger productivity boost than we saw historically because the prices of investment goods have declined more quickly. On the other hand, Bosler et al. (2017) argue that labor quality will add less per year to productivity growth than it has historically, since we will not repeat the massive 20th century increase in educational attainment. We discuss COVIDinduced disruptions to schooling in the next section.

${ }^{11}$ The very short-run effect of the pandemic on potential-in the second and third quarters of 2020 - was, arguably, extraordinary and unprecedented. For example, if lockdowns force businesses to close, one may want to interpret that as a reduction in full-employment output. We do not attempt here to quantify
} 
Great Recession.

Of course, the percentage point reduction is just the channels where we can gauge magnitudes (the known knowns). Panel B identifies some particularly salient additional channels that we can plausibly sign, but where the magnitude is uncertain (the known unknowns). Although some of these are near-term, most of them are likely to play out over longer periods of time. In addition, there are channels that we do not know how to sign because there are arguments on both sides.

In what follows, we discuss the different rows of the table. We organize our discussion under capital, labor, and TFP.

\subsection{Capital}

As already discussed, capital responds endogenously to TFP and to hours growth in the longer run. But in the near-term, business-cycle factors can affect investment, and hence capital accumulation and potential output. The pandemic has modestly reduced investment, including through heightened uncertainty. Lower investment reduces growth of $d k$ for the next few years.

We start by discussing how much measured capital input fell, based on the investment flows. But the post-pandemic growth of capital input is almost surely overstated because of the need to purchase duplicative capital to equip remote workers. We find that this duplicative-capital effect is quantitatively important.

The Fernald (2012) TFP database estimates capital input from quarterly investment flows for disaggregated types of capital. The data from February 4, 2021 has data through the end of 2020. Beyond the end of 2020, we can project capital input using investment forecasts. We use the February 2021 forecasts from IHS Market (Macroeconomic Advisers, or MA). We can then compare the data and projections to those using pre-pandemic investment projections using the February 2020 MA forecast. 
Between February 2020 and February 2021, the implied growth rate of business-sector capital input fell by about 0.4 percentage points in 2020 (the February 2020 MA investment forecast implied that capital services would rise 2.4 percent, which compares with an actual 2020 growth rate of 2 percent). With a capital share of 37 percent, the reduction in potential business-sector output from equation (1) is only 15 basis points. Since the business sector is only 75 percent of the total economy, the reduction in potential GDP in 2020 is only 0.1 percent. (These are the numbers shown in Table 2.) With the February 2021 MA forecast, about half of the shortfall relative to pre-pandemic expectations reverses in 2021, so even the 0.1 percentage point may be an overstatement. The rest of the shortfall reverses in 2022.

By comparison, the Great Recession saw a much greater shortfall of investment and capital accumulation. From 2008-2010, the cumulative shortfall of capital input growth, relative to the average growth rate in the 2005-07 period, was about $5 \frac{1}{2}$ percent. On its own, the capital channel thus reduced potential GDP by about $1 \frac{1}{2}$ percent $(5.5 \times 0.37 \times 0.75)$ relative to its pre-Great-Recession trend.

The effect on capital may seem surprisingly small in light of the survey evidence in Bloom et al. (2020b). That paper surveys Chief Financial Officers at a large number of U.K. firms. In that survey, investment as of 2020Q4 is expected to be about 20 percent lower than it would have been in the absence of COVID-19. A 20 percent decline in investment over this period would imply a much larger decline in capital input. But the decline in investment in the U.S. national accounts (and, even more puzzlingly, in the U.K. national accounts) is much smaller than implied by the U.K. company survey. Real U.S. nonresidential investment was only 1.3 percent lower in 2020Q4 than it was a year earlier-about 3 percentage points lower than the corresponding growth rate in 2019. Hence, the COVID-induced decline in investment over the entire course of 2020 was only a couple of percent, not 20 percent.

Of course, the pandemic experience is unusual in many ways, including in 
terms of capital. Much of the decline in capital input was obscured by the need to duplicate capital for remote workers. That is, "true" capital input growth is overstated in the near term by business's need to provide teleworkers with the equipment they require to do their jobs. For example, investment in computers and peripheral equipment rose at an eye-popping 84\% annual pace in Q2 and a $42 \%$ annual pace in Q3 (data as of January 29, 2021). The comparisons using actual 2020 investment, as well as MA's February 2021 investment forecasts for periods beyond 2020, include that duplication as part of $d k$. Potential output depends on the true stock of capital in use.

The data produced by Fernald (2012) maps each type of national-accounts investment into a perpetual inventory stock of that type of capital. For example, the stock of computers and peripheral equipment-that is, the perpetual inventory of the real investment flows-grew at $7.6 \%$ in 2020 and are forecast to grow at $12.2 \%$ in 2021 . Relative to pre-pandemic forecasts, these growth rates are more than 3 percentage points faster for 2020 and more than 8 percentage points faster for 2021. "Other" information processing equipment also grew faster than forecast. A reasonable estimate is that all of this post-pandemic increase in the growth of information-processing equipment is duplicative. That is, it was not an increase in "productive" capital input, since it simply replaced other capital that was idle. Without that increase, true capital input growth in 2020 and 2021 would be reduced by 0.4 by the end of 2021 .

This calculation ignores the fact that investment typically falls in downturns. If the correct non-pandemic counterfactual is that information-processing equipment growth would have slowed as much as it did during and immediately after the Great Recession, the duplicative capital estimate nearly doubles to about 0.8 percentage points.

From equation (1), any mismeasurement of input growth leads to mismeasurement of TFP growth. One might prefer to consider the capital stranded in office buildings as having temporarily or permanently depreciated, reducing true growth in capital input and, therefore, reducing $d k$ in equation 
(1). But most measures of capital input from a perpetual inventory use a constant depreciation rate, so the "error" shows up in the catch-all of measured TFP.

A 0.8 percentage point overstatement of capital growth in 2020 and 2021 would reduce measured total economy TFP growth — and potential output—by about 0.2 percent $(0.8 \times 0.37 \times 0.75)$. Intuitively, the same output appears to require additional capital input, which is why measured TFP falls. One These are the numbers we show in the duplicative capital row of Table 2.

We note two other considerations, which we do not quantify. First, in the long run, increased government debt may raise $r^{*}$ and crowd out private investment-reducing the longer-run level of potential output. On the other hand, real interest rates tend to stay low for an extended period after pandemics (Jordá et al., 2020a), possibly due to belief scarring that raises precautionary savings and labor supply. Increased precautionary saving would imply more capital growth, offsetting in whole or in part the first effect on the longer-run level of capital and potential. (Indeed, (Jordá et al., 2020a) find that GDP per capital rises in the years following pandemics.)

\subsection{Labor}

The pandemic adversely affected labor supply in multiple ways. In the near and medium term, widespread disruptions to business operations and increasing childcare needs prevent some individuals from working. In the long term, prolonged school closures may reduce human capital of the future workforce. In this section, we use the labor-quality framework of Bosler et al. (2017) to gauge plausible magnitudes of these channels. Namely, we calculate the impact on effective labor input $(d h+d l q)$ as the earnings-share-weighted average of changes in potential hours across demographic groups.

More precisely, the change in effective labor input is a weighted average of changes in potential hours across demographic groups, where the weights are 
the earnings share of each group:

$$
d l q+d h=\sum_{i=1}^{n} \frac{w_{i} H_{i}}{\sum_{j} w_{j} H_{j}} d h_{i}
$$

where for each worker-type $i, H_{i}$ is hours and $\frac{w_{i} H_{i}}{\sum_{j} w_{j} H_{j}}$ is earnings shares by age, education and gender groups used to construct the labor quality index in the Fernald/FRBSF TFP database. We average the earning shares over 2017- 2019 to remove noise.

\subsubsection{Closure of schools and daycare}

Since COVID began, a lot of attention has been paid to school and daycare closures. In the near and medium-run, studies such as Lofton, Petrosky-Nadeau and Seitelman (2021) find that increasing childcare needs constrained labor supply by parents, mainly mothers. This can lower potential output if some care givers loose attachment to the labor force. Table 3 displays an estimate of the share of individuals who are interested in working but are not working because of school-closure-induced childcare. We interpret this as a decline in the potential employment-to-population ratio through a reduction in the potential labor force. Overall, school-closure-related childcare may have reduced aggregate potential employment by 0.4 percentage points, with lower-wage female workers more affected. Effective labor input falls by slightly less 0.3 percent since there is a slight increase in labor quality for those who continue to work.

Furthermore, Fuchs-Schündeln et al. (2020) find that prolonged school closures can reduce the lifetime educational attainment of children today. Fernald, Li and Ochse (2021) aggregates their estimates of decline in educational attainment at the individual level to project the effect of potential employment in the long run - beyond 2030 or so. They find that school closures may depress labor input in 2045 by $1 / 2$ percentage point when the cohorts affected by school closures reach age 29 to 35 and can reduce potential 
output for over 70 years, until the affected cohort retires.

\subsubsection{Business closures}

Similarly, Table 4 displays an estimate of share of individuals who are interested in working but are not because of temporary and permanent employer closures due to the pandemic. Each cell reports the number of individuals who has not worked in the last 7 days because of temporary or permanent employer closure due to the pandemic divided by the total number of individuals excluding those who are not interested in working. The unit is percent.

Workers associated with permanently closed employers may face particularly high frictions to finding new employment, which may (temporarily) raise the natural rate of unemployment. Overall employment declined by about 0.8 percentage point due to permanent closures, with less educated workers being more affected. If we assume that, to first approximation, this leads to a structural reduction in employment for a time (see e.g. Kouchekinia et al. (2020)), then it lowers potential labor input by about $1 / 2$ percent.

\subsubsection{Early retirement}

Early retirement may hold down potential labor input in the medium run, most likely through the labor supply of workers currently aged 55 to 64 who are close to the retirement age. This group accounts for about one-sixth of the labor force in recent years. The labor force participation rate for workers aged 55-59 fell from a seasonally adjusted 73.0 percent (Jan to Mar 2020) to 71.4 percent (Nov 2020 to Jan 2021), leading to a 1.6 percentage point decline in participation. This amounts to 330,000 workers. Participation for the 60-64 age group fell by 1 percentage point from 57.4 percent to 56.4 percent, or 160,000 workers.

Assuming all these workers exit the workforce permanently and that early retirement is uncorrelated with workers income and mortality rate, we 
estimate that this channel lowers labor input in 2021 by about 0.2 percent and possibly smaller if early retirees earn less than the typical worker. Furthermore, this effect is not persistent because these workers would retire over the next decade without COVID. After accounting for retirement patterns before the pandemic, this channel may lower 2025-2026 labor input by 0.1 percent.

\subsubsection{Other channels}

Several factors could lead the near-term effects of business and school closures on labor inputs to become permanent. One is if people come to assume that pandemics may be a regular part of the new normal; then parents may feel it is more important to have one parent out of the labor force at home. A second is if firms increase automation to deal with uncertainties about worker availability and productivity because of the pandemic, or the risk of future pandemics (Leduc and Liu, 2020)

In the case of automation, the decline in labor input does not necessarily translate into a decline in potential output because automation increases labor productivity through a higher capital-labor ratio. Indeed, in the (Leduc and Liu, 2020) model, this substitution eventually raises potential output.

More generally, COVID-19 may affect the natural rate of unemployment. Some channels we discussed might temporarily show up in the natural rate, though others lead to a decline in the participation rate. In addition, uncertainty, the need for sectoral reallocation, and other increased search frictions might raise the natural rate. During the Great Recession, the natural rate plausibly increased by about 1 percentage point (Daly et al., 2012). However, Daly et al estimate that most of this increase reflected extended unemployment insurance benefits. With those benefits currently scheduled to expire, that channel is unlikely to be important today (Petrosky-Nadeau and Valletta, 2020). 


\subsection{Total factor productivity}

The level of TFP can easily be harmed in the short and medium run. From equation (1), any disruption that affects the ability to produce output from measured inputs will reduce TFP.

At the outset, we note that measured TFP fell 1.9 percent over the four quarters of 2020. ${ }^{12}$ But given the substantial cyclical effects on TFP (Fernald and Wang, 2016), it is hard to interpret this number in real time. Instead, in this section, we focus on potential channels.

Bloom et al. (2020b) estimate, from their survey of UK firms, that COVID-19 will reduce the medium-term (which they think of as 2022) level of TFP by about a percentage point. In our judgement, this is a plausible guess, though we can quantify only a part of it.

To start, one channel that we can quantify, as already noted, is duplicating capital to facilitate working from home. This shows up as lower measured TFP. Firms had to buy additional capital in order to allow workers to continue to produce at home. Intuitively, the same production required additional purchases of inputs of capital, reducing measured TFP. The estimate from Section 5 is that this effect may amount to 0.2 percent right now.

Perhaps more substantively, businesses have redirected costly time and resources to issues of health, cleaning, managing remote work, repatriating supply chains, and so forth. In the absence of the pandemic, these resources could have been devoted to direct production of final output. Quantitatively, if businesses spent $\$ 750$ per employee (including the value of management time), then it would amount to $0.5 \%$ of GDP. If the cost shows up as foregone output, or as additional input for the same output, then this is a drag on the

\footnotetext{
${ }^{12}$ Fernald (2012) data were accessed March 4, 2021. TFP was extraordinarily volatile over the course of the year-plunging 17 percent in the second quarter, and then rebounding 13 percent in the third quarter. The utilization adjustment in the dataset smooths the pattern, but utilization-adjusted TFP was estimated to decline 2.4 percent over the four quarters of 2020.
} 
level of TFP. ${ }^{13}$

To the extent these are a one-time expenses that temporarily reduce the level of TFP, potential TFP growth will be higher in future years when the level of TFP returns to where it would have been. Of course, if vaccines allow a return to the old normal, businesses might need to pay some additional adjustment costs in the future to re-adjust back.

Some of the costs could be ongoing, implying a more persistent (possibly permanent) effect on the level of TFP. For example, businesses might redesign offices and stores to allow more social distancing, even if it is less efficient; they might also shift from a "just in time" inventory model to a "just in case" model, with additional inventory holdings and more robust (but less efficient) supply

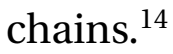

Reallocation from sectoral shifts can also lower TFP. Most obviously, sectors that are expanding may need to devote time and resources to meeting increases in demand, expanding capacity, and so forth.

Misallocation also affects the level of TFP. Many businesses have failed, and some have been formed. Depending on the relative productivity characteristics of the failing/starting firms, this could lead to "cleansing" or "sullying" (raising or lowering TFP) For manufacturing industries in the U.S. before the pandemic, Kehrig (2015) documents countercyclical productivity dispersion, contrary to "cleansing" effect in that productivity dispersion is countercyclical. One way to rationalize his findings is that inputs for starting a business or fixed costs are more expensive in a boom.

It is, of course, possible that the pandemic might to some extent accelerate innovation and raise potential TFP. For example, the pandemic has forced firms to experiment with new ways of doing business. This is an investment in intangible knowledge that might not otherwise have taken place, or perhaps

\footnotetext{
${ }^{13}$ Bloom et al. (2020b) emphasize the need to purchase additional intermediate inputs, such as cleaning services, in order to produce any level of sales. These additional purchase reduce TFP.

${ }^{14}$ Acemoglu and Tahbaz-Salehi (2020) model how specialized supply chains may raise productivity but also increase fragility.
} 
would have happened more slowly. The resulting knowledge-as well as social coordination on new modes-may raise efficiency even if we return to the old normal. For example, as businesses have coordinated on videoconferencing for important meetings, it may permanently reduce some of the need for costly business travel.

\section{Longer run growth and COVID-19 risks}

In contrast to the clear likelihood of near- and medium-term effects on the level of potential, it is less clear that longer-run growth will be substantially affected by COVID-19. In the long run, as discussed in Section 2, growth depends primarily on TFP and demographics. We do not expect COVID-19 to substantially change demographics in a way that would lead to a substantial change in future (slow) hours growth. So we focus this section on growth in TFP and, as in equation (4), labor productivity.

As discussed in Section 3, the U.S. economy has been in a "slow productivity growth" regime since around 2004, with GDP per hour rising at about a 1.2 percent annual pace through 2019 (see Table 1). As noted in that section, in post- war U.S. data, growth regimes have typically lasted decades (the exception is the shorter fast- growth 1995-2004 period).

Our modal projection, in the absence of the pandemic, was that slow productivity growth plus slow growth in demographics implied longer-run GDP growth of 1.55 percent (Table 1, final row). That corresponds to the slope of the blue "pre-pandemic trajectory" line in Figure 1.

Of course, any $g^{*}$ estimate is inherently subject to enormous uncertainty. But We do not see a clear reason to expect COVID-19 to substantially change the growth trajectory. That is, in terms of Figure 1, we expect eventually to be on the red line, even if we don't return to the blue line. Still, we can identify some risks to the growth trajectory that could push us to the dashed line.

In the endogenous-growth literature, long run growth reflects ideas. 
Historically, the innovation channel contributed to $80 \%$ of output per person growth in the US. New ideas, in turn, depend on the ideas production function, which we write as:

$$
\frac{d A}{A}=\beta R A^{\phi-1}
$$

where $R$ is the number of researchers or research input and $A$ is the stock of ideas. The term $d A / A$ is the flow of new ideas produced over time expressed as a rate relative to the stock of existing ideas. A higher rate of new ideas raises labor productivity growth rate in the long run. The parameter $\phi$ captures how the state of technology affects the ease of innovation. $\phi<1$ represents ideas becoming harder to find as technology progresses (Bloom et al., 2020a).

Whether COVID affects the long run growth depends on how it affects the ideas production function (6). On a balanced growth path with a constant growth rate of $A$, the growth rate is given by

$$
\frac{d A}{A}=\frac{1}{1-\phi} \frac{d R}{R}
$$

That is, factors affecting the scale parameter $\beta$ do not affect the long run growth rate. For example, widespread telecommuting could reduce the kinds of informal interactions that spur the creation and diffusion of ideas within companies or cities. ${ }^{15}$ If this only lowers $\beta$, then it may temporarily lower the growth rate of ideas but not affect the steady state growth rate. On the other hand, it can also affect the steady state growth rate if it makes ideas harder to find and slower to diffuse (lowers $\phi$ ).

On a more optimistic note, businesses may find adequate substitutes for in-person interactions. Moreover, the ability to telecommute may open up a wider availability of specialized talent to businesses boosts $d R / R$ temporarily and generating a burst of ideas growth.

Other risk factors include changes to global idea diffusion, rate of adoption

\footnotetext{
${ }^{15} \mathrm{Abel}$ et al. (2012) find that city productivity is related to density.
} 
of some existing ideas (e.g., online shopping and reduced business travel ${ }^{16}$ ), take up of AI and automation.Research efforts may also change if businesses cut spending on $R \& D$ or intangible organizational capital and redirect research spending towards health, vaccines, and so forth. In the absence of COVID-19, this research effort could go elsewhere.

One clear risk to research effort is reduced intangible investments. Bloom et al. (2020b) find a sharp decline in R\&D post-COVID, on the order of 10 percent. Nevertheless, despite this survey evidence, we do not see this as a major risk yet. In U.S. data, the post-COVID reduction in R\&D capital growth (calculated as in Section 4.1 is modest. Using the IHS Market (MA) investment forecasts, the implied stock of R\&D capital is only slightly reduced by the end of 2021 and is essentially unchanged by the end of 2022 .

Perhaps more importantly, Bloom et al. (2020b) also find that executives report spending about a third of their time managing COVID, which leaves less time for them to think about other strategic issues in the firm. The reduced intangible investment from managerial time is a real risk for the next few years. That said, this channel is likely to largely disappear as COVID-19 becomes a less salient issue for businesses.

\section{Conclusion}

This paper provides a simple accounting framework for understanding the channels through which COVID-19 may affect potential output. Where possible, we also gauge plausible magnitudes and direction of effects. Overall, we find that pandemic is likely to modestly reduce the level of potential output in the next few years. Although there are many upside and downside risks, there is little reason to think the pandemic will substantially change the underlying slow-growth trajectory that the US economy was in before the

\footnotetext{
${ }^{16}$ Andersen and Dalgaard (2011) find empirically that increased business travel boosts growth, which they attribute to increased diffusion.
} 
pandemic.

Ultimately, the magnitude of the effects depends on the path of the virus as well as the economic policies we implement. For example, the efficacy and speed of vaccination, short-term fiscal and monetary stimulus help determine the speed of the recovery and the degree of scarring. Other policies, such as around childcare, could also mitigate some of the effects on labor supply.

The flip-side of our finding of modest effects on potential output is that much of the large near term output decline reflects an increase in slack in the economy (a more negative output gap). In turn, more slack implies less inflation risk going forward.

\section{References}

Abel, Jaison R., Ishita Dey, and Todd M. Gabe, "Productivity And The Density Of Human Capital," Journal of Regional Science, October 2012, 52 (4), 562586.

Acemoglu, Daron and Alireza Tahbaz-Salehi, "Firms, Failures, and Fluctuations: The Macroeconomics of Supply Chain Disruptions," Working Paper 27565, National Bureau of Economic Research July 2020.

Andersen, Thomas and Carl-Johan Dalgaard, "Flows of people, flows of ideas, and the inequality of nations," Journal of Economic Growth, March 2011, 16 (1), 1-32.

Bloom, Nicholas, Charles I Jones, John Van Reenen, and Michael Webb, "Are ideas getting harder to find?," American Economic Review, 2020, 110 (4), 110444 .

_ , Philip Bunn, Paul Mizen, Pawel Smietanka, and Gregory Thwaites, "The impact of Covid-19 on productivity," Technical Report, National Bureau of Economic Research 2020. 
Bosler, Canyon, Mary C. Daly, John G. Fernald, and Bart Hobijn, "The Outlook for U.S. Labor-Quality Growth," in "Education, Skills, and Technical Change: Implications for Future US GDP Growth" NBER Chapters, National Bureau of Economic Research, 2017.

CBO, "An Overview of the Economic Outlook: 2021 to 2031," February 2021.

Cerra, Valerie, Antonio Fatás, and Sweta Saxena, "Hysteresis and Business Cycles,” CEPR Discussion Papers 14531, C.E.P.R. Discussion Papers March 2020.

Daly, Mary C, Bart Hobijn, Ayşegül Şahin, and Robert G Valletta, "A search and matching approach to labor markets: Did the natural rate of unemployment rise?," Journal of Economic Perspectives, 2012, 26 (3), 3-26.

Fernald, John, "A Quarterly, Utilization-Adjusted Series on Total Factor Productivity," Federal Reserve Bank of San Francisco Working Papers, 2012, 2012-19.

Fernald, John G., "Productivity and Potential Output before, during, and after the Great Recession," NBER Macroeconomics Annual, 2015, 29 (1), 1-51.

_ , "Reassessing Longer-Run U.S. Growth: How Low?," Working Paper Series 2016-18, Federal Reserve Bank of San Francisco August 2016.

- and Charles I. Jones, "The Future of US Economic Growth," American Economic Review, May 2014, 104 (5), 44-49.

- and Huiyu Li, "Is Slow Still the New Normal for GDP Growth?," FRBSF Economic Letter, 2019.

_ and J. Christina Wang, "Why Has the Cyclicality of Productivity Changed? What Does It Mean?," Annual Review of Economics, 2016, 8 (1), 465-496.

_, Huiyu Li, and Mitchell Ochse, "Future Output Loss from COVID-Induced School Closures," FRBSF Economic Letter, 2021, (4). 
_ , Robert E. Hall, James H. Stock, and Mark W. Watson, "The Disappointing Recovery of Output after 2009," Brookings Papers on Economic Activity, 2017, 48 (1 (Spring), 1-81.

Foerster, Andrew and Christian Matthes, "Learning about Regime Change," Working Paper Series 2020-15, Federal Reserve Bank of San Francisco April 2020.

Fuchs-Schündeln, Nicola, Dirk Krueger, Alexander Ludwig, and Irina Popova, "The Long-Term Distributional and Welfare Effects of Covid-19 School Closures," Technical Report w27773, National Bureau of Economic Research September 2020.

Jones, Charles I., "Sources of U.S. Economic Growth in a World of Ideas," American Economic Review, March 2002, 92 (1), 220-239.

Jorgenson, Dale W., Frank M. Gollop, and Barbara M. Fraumeni, Productivity and U.S. economic growth Harvard economic studies, Harvard University Press, 1987.

Kahn, James A. and Robert W. Rich, "Tracking the new economy: Using growth theory to detect changes in trend productivity," Journal of Monetary Economics, 2007, 54 (6), 1670-1701.

Kehrig, Matthias, "The Cyclical Nature of the Productivity Distribution," SSRN Scholarly Paper ID 1854401, Social Science Research Network, Rochester, NY January 2015.

Kiley, Michael T., “Output gaps,” Journal of Macroeconomics, 2013, 37, 1 - 18.

Kouchekinia, Noah, Marianna Kudlyak, Mitchell Ochse, and Erin Wolcott, "Temporary Layoffs and Unemployment in the Pandemic," FRBSF Economic Letter, 2020, 2020 (34), 01-05. 
Leduc, Sylvain and Zheng Liu, "Robots or Workers? A Macro Analysis of Automation and Labor Markets," in "in” Federal Reserve Bank of San Francisco 2020.

Lofton, Olivia, Nicolas Petrosky-Nadeau, and Lily Seitelman, "Parents in a Pandemic Labor Market," Federal Reserve Bank of San Francisco working paper 2021-04, 2021.

Peters, Michael and Conor Walsh, "Declining Dynamism, Increasing Markups and Missing Growth: The Role of the Labor Force," SSRN Electronic Journal, 2019.

Petrosky-Nadeau, Nicolas and Robert G Valletta, "Did the $\$ 600$ Unemployment Supplement Discourage Work?," FRBSF Economic Letter, 2020, 2020 (28), 01-05.

Óscar Jordá, Sanjay R. Singh, and Alan M. Taylor, "Longer-run economic consequences of pandemics," CEPR Discussion Papers 14543, C.E.P.R. Discussion Papers June 2020.

_ , - , and _ , "The Long-Run Effects of Monetary Policy," Working Paper Series 2020-01, Federal Reserve Bank of San Francisco January 2020. 


\section{Table 2: Summary of effects on potential output}

Panel A. Channels for which we can gauge plausible magnitudes

\begin{tabular}{|c|c|c|c|c|c|}
\hline Channel & Horizon & $d y^{\star}$ & $d k$ & $d h^{\star}+d l q^{\star}$ & $d t f p^{\star}$ \\
\hline Uncertainty/recession reduce investment & Near, medium & -0.1 & -0.5 & & \\
\hline $\begin{array}{l}\text { Duplication of capital from WFH }(\rightarrow \text { less } \\
\text { "true" prod. capacity } K \text {; higher measured } K \\
\text { reduces } T F P \text { ) }\end{array}$ & Near & -0.2 & & & -0.2 \\
\hline Childcare needs reduce LF participation & Near & -0.2 & & -0.3 & \\
\hline Permanent business closures $\rightarrow$ LT unempl. & Near & -0.3 & & -0.5 & \\
\hline Early retirements & Near, medium & -0.15 & & -0.2 & \\
\hline School closures reduce future human capital & Very long & -0.5 & -0.5 & -0.5 & \\
\hline
\end{tabular}

Panel B. Channels we can plausibly sign

\begin{tabular}{|c|c|c|c|c|c|}
\hline Channel & Horizon & $d y^{\star}$ & $d k$ & $d h^{\star}+d l q^{\star}$ & $d t f p^{\star}$ \\
\hline Increased labor-market frictions & Near, medium & - & & - & \\
\hline Adjustment costs from shift to WFH & Near & - & & & - \\
\hline $\begin{array}{l}\text { Firms learn new ways of doing business } \\
\text { remotely }\end{array}$ & Medium, long & + & & & + \\
\hline Belief scarring increases risk aversion & Medium, long & $?$ & + & + & $?$ \\
\hline Automation & Medium, long & + & + & - & \\
\hline Government debt crowds out investment & Long & - & - & & \\
\hline
\end{tabular}

Panel C. Channels we do not know how to sign

Channel

Allocative efficiency

Shift to widespread telecommuting

Change in research efforts
Potential effects

Probably lowers $Y$ in the near and medium term

Ambiguous effects on idea creation and diffusion in the long run

Redirecting research to vaccines may raise or lower innovation, depending on the relative marginal values of vaccine research versus other. Accelerated adoption of some COVID-robust technologies (e.g., automation, AI) may boost growth.

Notes: In each row, $d y^{\star}$ is the sum of the contributions of inputs ( $d k$ or $\left.d h^{\star}+d l q^{\star}\right)$ or $d t f p^{\star}$. The units in Panel A are percent deviation from a pre-pandemic benchmark for the level of potential. We think of near and medium term effects as applying to the 2021 level. Mediumterm effects continue (and may worsen) for several additional years. Near-term effects may persist as well, particularly if the recovery is subdued. Long-term effects apply beyond 2026. The school-closure/human capital effect refers to 2045 (the effect for the next decade or so are minimal). The final two rows in Panel $\mathrm{C}$ refer to growth effects through the pace of innovation. 
Table 3: \% of labor force not working due to COVID-related school closures

\begin{tabular}{lccc}
\hline & $\begin{array}{c}\text { High school or } \\
\text { less }\end{array}$ & $\begin{array}{c}\text { More than high } \\
\text { school }\end{array}$ & All \\
\cline { 2 - 3 } Male & 0.2 & 0.2 & 0.2 \\
Female & 1.1 & 0.5 & 0.7 \\
All & 0.6 & 0.3 & 0.4 \\
\hline
\end{tabular}

Source: US Census, Household Pulse Survey week 23 Jan 20-Feb 1, 2021

Table 4: \% of labor force not working due to COVID-related business closures

\begin{tabular}{lcccc}
\hline & $\begin{array}{c}\text { High school or } \\
\text { less }\end{array}$ & $\begin{array}{c}\text { More than high } \\
\text { school }\end{array}$ & All \\
\cline { 2 - 3 } $\begin{array}{l}\text { Temporary } \\
\text { closure }\end{array}$ & 2.1 & & 1.3 & 1.6 \\
$\begin{array}{l}\text { Permanent } \\
\text { closure }\end{array}$ & 1.1 & 0.6 & 0.8 \\
\cline { 1 - 2 } & & & \\
\hline
\end{tabular}

Source: US Census, Household Pulse Survey week 23 Jan 20-Feb 1, 2021 